\title{
BMJ Open Short-term exposure to pollen and the risk of allergic and asthmatic manifestations: a systematic review and meta-analysis
}

Milja A Kitinoja, Timo T Hugg, Nazeeba Siddika, Daniel Rodriguez Yanez, Maritta S Jaakkola, Jouni J K Jaakkola

To cite: Kitinoja MA, Hugg TT, Siddika N, et al. Shortterm exposure to pollen and the risk of allergic and asthmatic manifestations: a systematic review and meta-analysis. BMJ Open 2020;10:e029069. doi:10.1136/ bmjopen-2019-029069

- Prepublication history and additional material for this paper are available online. To view these files, please visit the journal online (http://dx.doi. org/10.1136/bmjopen-2019029069).

Received 10 January 2019 Revised 19 0ctober 2019 Accepted 19 November 2019

Check for updates

(c) Author(s) (or their employer(s)) 2020. Re-use permitted under CC BY-NC. No commercial re-use. See rights and permissions. Published by BMJ.

Center for Environmental and Respiratory Health Research, University of Oulu, Oulu, Finland

Correspondence to

Professor Jouni J K Jaakkola; jouni.jaakkola@oulu.fi

\section{ABSTRACT}

Background Several studies have assessed effects of short-term exposure to pollen on allergic and asthmatic manifestations. The evidence is inconclusive, and no metaanalysis has been published.

Objective To synthesise the evidence on the relations between short-term pollen exposure and the risk of allergic and asthmatic manifestations.

Methods We performed a systematic literature search of PubMed and Scopus databases up to the end of August 2018. In addition, we reviewed the reference lists of relevant articles. Two authors independently evaluated the eligible articles and extracted relevant information in a structured form. We calculated summary effect estimates (EE) based on the study-specific ORs and regression coefficients $(\beta)$ by applying both fixed-effects and randomeffects models.

Results 26 studies met the a priori eligibility criteria, and 12 of them provided sufficient information for the metaanalysis. The summary EE related to 10 grains per $\mathrm{m}^{3}$ increase in pollen exposure showed an $1 \%$ increase (EE $1.01,95 \% \mathrm{Cl} 1.00$ to 1.02 ) in the risk of lower respiratory symptoms and a $2 \%$ increase (EE 1.02, 95\% Cl 1.01 to 1.03 ) in the risk of any allergic or asthmatic symptom. Correspondingly, the risk of upper respiratory symptoms and ocular symptoms increased 7\% (EE 1.07, 95\% Cl 1.04 to 1.09 ) and $11 \%$ (EE $1.11,95 \% \mathrm{Cl} 1.05$ to 1.17$)$, respectively, in relation to such pollen exposure. Shortterm exposure to pollen did not show any significant effect on daily lung function levels.

Conclusion Our results provide new evidence that shortterm pollen exposure significantly increases the risks of allergic and asthmatic symptoms.

\section{INTRODUCTION}

Allergy and asthma are common diseases and consequently, of public health importance globally. Approximately 500 million people suffer from allergic rhinitis worldwide and more than 300 million people have asthma. ${ }^{1-3}$ The prevalence of rhinitis and/or rhinoconjunctivitis varies globally between $1 \%$ and $45 \%^{4}$ and that of asthma between $1 \%$ and $21 \% .^{5}$ In Western Europe, the prevalence of
Strengths and limitations of this study

- Identification of individual studies based on a clearly defined and extensive search strategy based on a priori set inclusion and exclusion criteria.

- In addition, secondary references were included.

- The study-specific effect estimates were converted into comparable effect estimates for exposure corresponding to 10 pollen grains increase per cubic metre of air.

- Publication bias was assessed by visual inspection of the funnel plots and by applying Begg's and Egger's tests.

- The number of studies available for the subanalyses investigating effects on various outcomes was quite low.

allergic rhinitis and/or rhinoconjunctivitis ranges from $17 \%$ to $29 \%$ and the prevalence of asthma from $6 \%$ to $18 \%{ }^{7}$ Respectively, the prevalence of rhinitis and/or rhinoconjunctivitis and asthma are $12 \%-30 \%{ }^{8}$ and $5 \%-10 \%$ in the USA. ${ }^{9}$

The prevalence of physician-diagnosed pollen-induced allergic rhinitis was $18.5 \%$ among people living in northern China. ${ }^{10}$ The majority of individuals suffering from allergic rhinitis experience seasonal symptoms when exposed to pollen. ${ }^{11}$ Correspondingly, exposure to pollen grains increases the risk of asthma exacerbations among asthmatic persons. ${ }^{12}$ There are no universally accepted, clinically meaningful threshold levels for pollen exposure. In previous studies, threshold levels have varied between 30 and 60 pollen grains per cubic metre of air. ${ }^{13}{ }^{14}$ However, exposures to relatively low levels of pollen (6-9 grains $/ \mathrm{m}^{3}$ ) have been associated with asthma symptoms among those who already have this disease. ${ }^{15}$ Pollen allergy has been found in $80 \%-90 \%$ of children suffering from asthma and in $40 \%-50 \%$ of adult-onset asthmatics. ${ }^{16}$ 


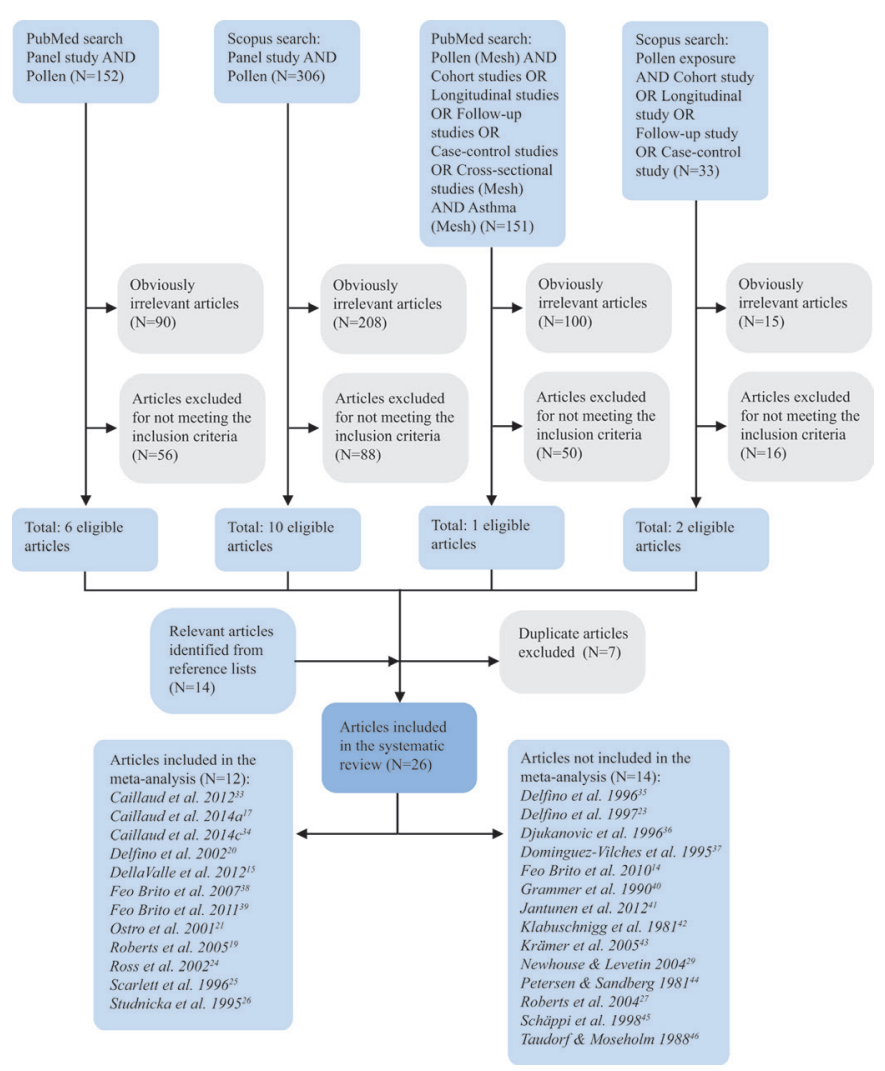

Figure 1 Flow diagram showing searches and study selection.

Several panel studies have suggested an association between short-term exposure to pollen and allergic/asthmatic manifestations, although the magnitude and statistical significance of such estimated relations have varied. ${ }^{17-21}$ Lung function levels have not been found to clearly associate with pollen exposure. ${ }^{22-26}$ However, the amount of exhaled nitric oxide $(\mathrm{NO})^{22}{ }^{27}$ and allergy and/or asthma medication use ${ }^{1824}$ seem to increase during pollen season. Caillaud $e t a t^{28}$ reviewed qualitatively three panel studies that provided some evidence on a relation between daily counts of atmospheric pollen and occurrence of health outcomes.

The panel studies on pollen exposure and manifestations of asthma or allergy have provided somewhat conflicting results. ${ }^{2329}$ To our knowledge, there are no previous systematic reviews with meta-analysis that have assessed the effects of short-term pollen exposure on the risk of allergic and asthmatic symptoms and lung function. Therefore, we conducted a systematic review and meta-analysis to summarise the existing evidence on the relations between short-term exposure to pollen and the occurrence of various allergic and asthmatic symptoms and/or lung function manifestations.

\section{METHODS}

This systematic review and meta-analysis is based on a review protocol accessible online (http://www.oulu.fi/ cerh/node/50459).

\section{Search strategy and eligibility criteria}

We performed a systematic literature search of PubMed and Scopus databases up to the end of August 2018, as shown in figure 1 . In the first phase, we used the search terms "panel study" and "pollen". In order to have a more extensive data search, we included the terms "pollen exposure", "asthma", "cohort study", "longitudinal study", "follow-up study", "case-control study" and "cross-sectional study" in the second search (online supplementary table 1). All languages were included in the search.

Studies that met the following a priori eligibility criteria were included in this systematic review: the study (1) was an original study; (2) was a panel study where a group of people were followed longitudinally over a certain time period; (3) included allergic or asthmatic symptoms or measurements of lung function as the outcome; (4) included a study population of children or adults or both and (5) reported on relations between daily mean airborne pollen exposure and manifestations of allergies and/or asthma.

Articles that were obviously irrelevant were excluded applying title screening. Articles that did not meet our a priori inclusion criteria were excluded by reading the abstract or full text.

\section{Outcome and exposure definitions}

The outcome of interest was occurrence of allergy and/ or asthma manifestations. The definitions of allergy and asthma manifestations included self-reported or parentreported symptoms (lower and upper respiratory tract symptoms, ocular symptoms, skin symptoms and/or symptom scores), lung function measurements (peak expiratory flow (PEF), forced expiratory volume (FEV), forced vital capacity, (FVC), exhaled NO) and use of allergy and/or asthma medications. The exposure of interest was exposure to pollen, expressed as the amount of pollen grains per cubic metre of air sampled (grains/ $\mathrm{m}^{3}$ ). The eligible definition of exposure included exposure to mean daily total airborne pollen or exposure to mean daily airborne pollen of distinct types (including birch, grass, ragweed, mugwort, olive, elm and/or hazel/ alder pollen). All the available studies assessed the associations between pollen concentrations and symptoms during the same day, that is, the duration of short-term exposure was here 1 day.

\section{Data extraction and quality assessment}

Eligible studies were examined and their relevant characteristics recorded in a standardised data extraction form independently by two authors (MAK and DRY). Any disagreements were discussed together with additional two authors at the end of the data extraction process (TTH and JJKJ) until a consensus was achieved. Table 1 displays the main characteristics of the eligible studies. The study quality was assessed applying the NewcastleOttawa Scale (NOS) with the maximum score of 9.

In one study, the occurrence of allergic and asthmatic symptoms in relation to pollen exposure was investigated 


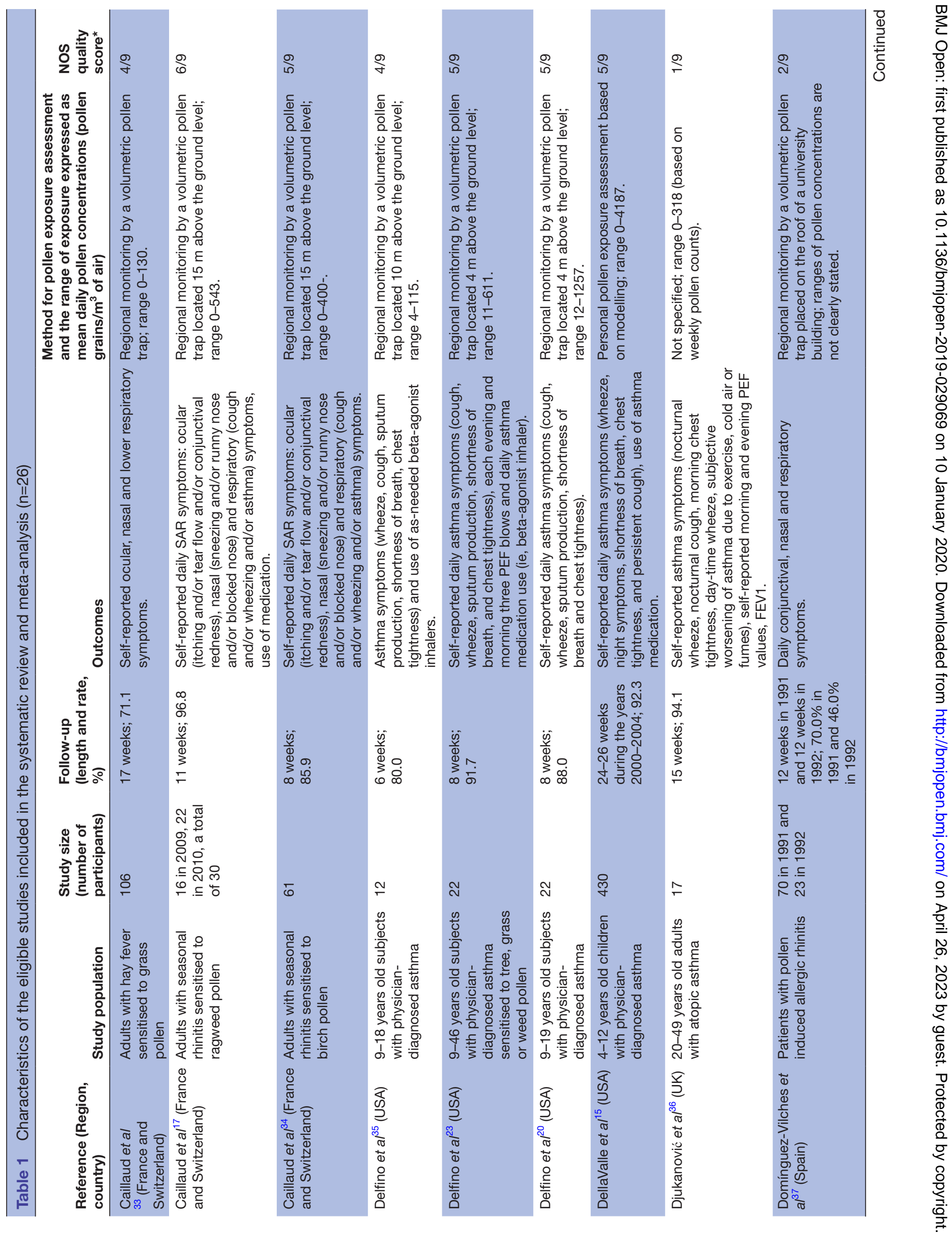




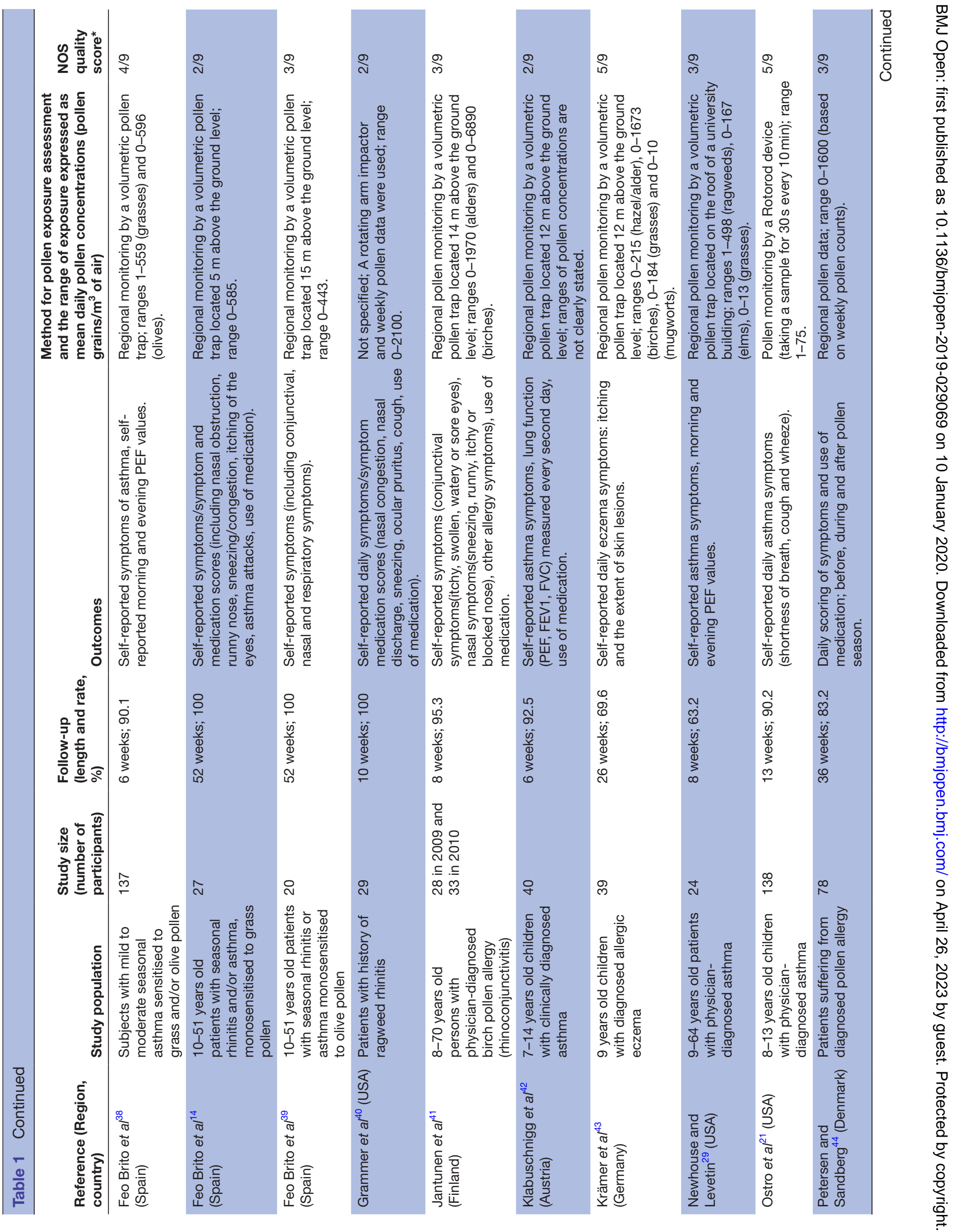




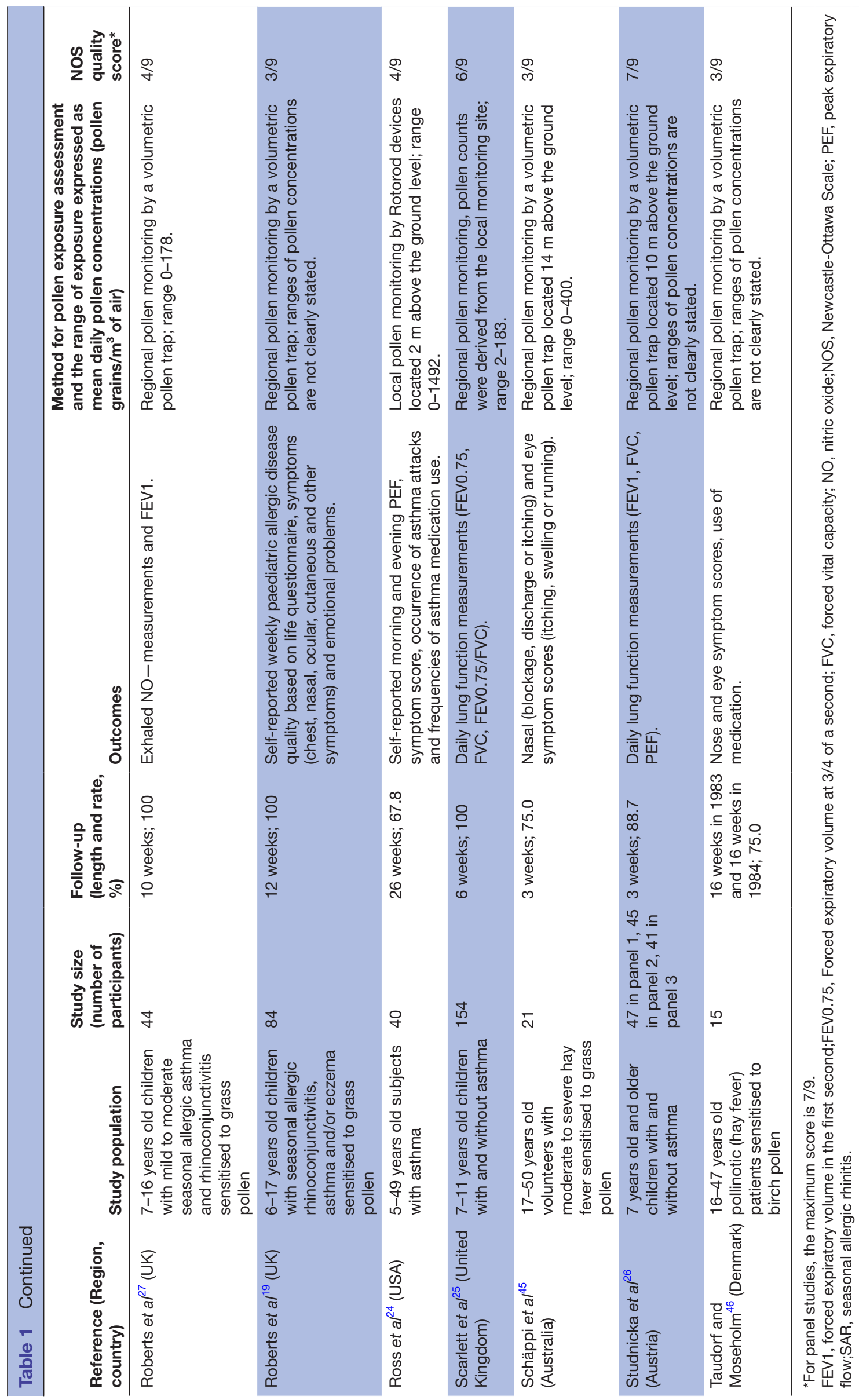


by recruiting a group of study subjects in two consecutive years. ${ }^{17}$ There was some overlap among the study subjects, so that seven individuals (23\% of participants) were included in both of these study groups. These two groups provided independent effect estimates (EEs) for our meta-analysis. In another study, subjects were recruited in three distinct but successive periods of time within the pollen season..$^{26}$ These three groups also provided three independent EEs for the meta-analyses. The protocol was conducted according to Preferred Reporting Items for Systematic Reviews and Meta-Analyses guidelines. ${ }^{30}$

\section{Statistical methods}

In the meta-analysis, we calculated summary EEs from the study-specific ORs or regression coefficients $(\beta)$ by using fixed-effects and random-effects models. When available, we preferred the adjusted EEs to the crude estimates. The summary EE from the fixed-effects model is presented when the study-specific EEs were homogeneous, whereas the summary EE from the random-effects model is presented when moderate or substantial heterogeneity was observed between the study-specific estimates. Heterogeneity was evaluated using the $Q$ and $I^{2}$-statistics. $\mathrm{I}^{2}$ statistic $>50 \%$ indicates high, $25 \%-50 \%$ moderate and $<25 \%$ low heterogeneity. Publication bias was assessed by visual inspection of the funnel plots and application of Begg's and Egger's tests. ${ }^{31}{ }^{32}$ Individual studies included in the meta-analysis assessed their EEs in relation to different levels of pollen exposure. Because of this, individual EEs were converted into a common pollen concentration, that is, as 10 pollen grains increase per cubic metre of air, before estimating the summary effect.

Because of only a small number of studies or inadequacy of data in the existing studies, we were not able to analyse potential relations between pollen exposure and skin symptoms, FVC, exhaled NO or allergy and/or asthma medications. The panel studies with allergic and/or asthmatic populations examined usually allergy-related and asthma-related symptoms as outcomes. In panel studies including general populations, the outcomes were lung function measurements. We used the 'metan' command of the Stata V.11 statistical program to analyse the fixed and random effects (StataCorp).

\section{Patient and public involvement}

Due to the nature of systematic review and meta-analysis, there was no patient and public involvement in this study.

\section{RESULTS}

\section{Literature search}

Reference lists of the articles that fulfilled the eligibility criteria were also reviewed and additional 14 articles fulfilling the criteria were included. Seven duplicate studies were excluded. A step-by-step approach of the literature search is presented in figure 1. Twenty-six studies met the a priori inclusion criteria and were included in the systematic review, while 12 studies of them were included in the quantitative meta-analysis. Table 1 displays the characteristics of the 26 eligible studies. ${ }^{14} 1517$ 19-21 23-27 29 33-46

Ten of the 26 studies specifically investigated the relation between total pollen exposure and allergic and/ or asthmatic manifestations. Thirteen reported on grass (Poaceae), five on birch (Betula), five on ragweed (Ambrosia), three on hazel/alder (Corylus/Alnus), three on olive (Olea), two on elm (Ulmus) and one on mugwort (Artemisia) exposure and allergy and/or asthma manifestations.

\section{Characteristics of included studies}

Characteristics of the 26 eligible studies are shown in table 1. In 13 studies, subjects were asthmatics, in 11 studies, subjects were sensitised to pollen (ie, positive skin prick test (SPT) or Allergen-Specific IgE test) and in 8 studies, subjects had hay fever (ie, allergic rhinitis, pollen allergy and pollinosis). One study investigated subjects with eczema. In two studies, subjects with and without asthma were analysed together without taking into account the prior disease status. Ten studies investigated children, four adults and nine both children and adults. In three studies, authors did not specify the age of the subjects. Six studies applied logistic regression, nine studies linear regression, two studies Poisson regression and two studies time series regression for the analyses. The NOS scores varied between studies from one to seven of total nine.

The studies defined the allergic and/or asthmatic manifestations in different ways. Sensitisation based on SPT or IgE analysis was the most common criterion used for the definition of allergy. Current presence of asthma, previous history of asthmatic symptoms and/or physician (ie, clinical) diagnosis were frequently applied as inclusion criteria in the reviewed studies. We systematically categorised outcomes into any symptom, lower respiratory tract symptoms, upper respiratory tract symptoms, ocular symptoms, skin symptoms, symptom scores, lung function measurements (PEF, FEV, FVC and exhaled NO) and use of allergy and/or asthma medications.

Pollen monitoring used for exposure assessment was based on regional sampling in 21 studies, on local sampling in 2 studies and on personal exposure modelling in 1 study. In two studies, authors did not specify the type of pollen sampling. The height of the pollen sampler varied between 2 and $15 \mathrm{~m}$ above the ground level. Thirteen of the studies did not give the height information for pollen sampler. Twenty-five studies expressed the mean pollen concentration as pollen grains per cubic metre of air per 24 hours. In three studies, daily pollen counts were converted into weekly pollen sums, and consequently, the relations between weekly pollen counts and weekly symptoms were presented. In two studies, hourly/bihourly pollen counts were presented in addition to daily counts. Main outcomes for the studies that were not included into the meta-analysis are presented in table 2. 
Table 2 The main findings in articles not included into the meta-analysis $(n=14)$

\begin{tabular}{ll} 
Reference & Main findings \\
\hline Delfino et al $^{35}$ & Pollen exposure was not associated with either asthma symptom scores or as-needed beta-agonist \\
& inhaler use.
\end{tabular}

Delfino et $a^{23} \quad$ Pollen exposure was not associated with asthma symptom severity, morning or evening peak expiratory flow rate, or $\beta$-agonist inhaler use.

Djukanovic et $a^{36} \quad$ The peak pollen season was associated with a significant increase in asthma symptoms ( $\left.\mathrm{p}<0.05\right)$.

Dominguez-Vilches et A greater seasonal pollen intensity was associated with a higher occurrence of daily symptoms. $a l^{37}$

\begin{tabular}{|c|c|}
\hline Feo Brito et $\mathrm{al}^{14}$ & $\begin{array}{l}\text { A significant positive association was found between the presence of symptoms and pollen grains } \\
(r=0.62 ; p<0.001) \text {. }\end{array}$ \\
\hline Grammer et al ${ }^{40}$ & $\begin{array}{l}\text { The peak pollen periods were associated with a twofold increase in symptom-medication scores } \\
\text { among a subset of patients. }\end{array}$ \\
\hline Jantunen et $a l^{41}$ & $\begin{array}{l}\text { The no of subjects with allergy symptoms increased significantly with the daily pollen concentrations } \\
(r=0.35-0.36, p<0.01) \text {. }\end{array}$ \\
\hline Klabuschnigg et $\left.a\right|^{42}$ & $\begin{array}{l}\text { Two hourly pollen counts or daily pollen counts were not associated with the frequency of asthma } \\
\text { attacks. In contrast, consecutive } 10 \text { days mean symptom scores (assessing asthma attacks) } \\
\text { associated with the total pollen counts. No associations were found between pollen exposure and } \\
\text { lung function measurements (including PEF, FEV1 and FVC). }\end{array}$ \\
\hline
\end{tabular}

Krämer et $a l^{43} \quad$ Pollen exposure had no significant effect on skin symptom severity among children with winter type eczema (relative change in grass pollen exposure $0.98-1.00 ; 95 \%$ confidence limits 0.81 to 1.18 ). In contrast, grass-pollen exposure showed a significant effect on the severity of skin symptoms among children with summer type eczema (relative change in grass pollen exposure 1.16-1.19; 95\% confidence limits 1.02 to 1.39 ).

Newhouse and Levetin Ambrosia pollen concentrations were significantly correlated with composite asthma scores ( $r=0.263$, 29 $\mathrm{p}<0.05)$, rhinitis scores $(\mathrm{r}=0.513, \mathrm{p}<0.001)$ and several individual symptoms. Chenopodiaceae/ Amaranthaceae pollen concentrations showed significant associations with composite asthma scores $(r=0.256, p<0.05)$. Ulmus $(r=0.367, p<0.01)$, Chenopodiaceae/Amaranthaceae $(r=0.458, p<0.001)$ and Poaceae $(r=0.326, p<0.05)$ pollen concentrations showed significant correlations with composite rhinitis scores. Pollen concentrations significantly influenced morning (but not evening) PEF values measured in the following day $(r=-0.261--0.364, p<0.05-0.01)$.

\begin{tabular}{|c|c|}
\hline $\begin{array}{l}\text { Petersen and } \\
\text { Sandberg }\end{array}$ & $\begin{array}{l}\text { ere was a positive association between the appearance of pollen grains in th } \\
\text { mptom-medication score. }\end{array}$ \\
\hline Roberts et $a l^{27}$ & $\begin{array}{l}\text { Fractional exhaled nitric oxide levels increased significantly during the grass pollen season (median } \\
\text { change } 2.9 \mathrm{ppb}, 95 \% \mathrm{Cl} 1.5 \text { to } 5.4) \text {. There were no apparent associations between pollen counts and } \\
\text { other lung function measurements. }\end{array}$ \\
\hline Schäppi et $a l^{45}$ & $\begin{array}{l}\text { The grass pollen counts associated significantly with the average nasal }(r=0.637, p<0.001) \text { and eye } \\
\text { symptom }(r=0.586, p<0.005) \text { scores. }\end{array}$ \\
\hline Tauc & $\begin{array}{l}\text { Occurrence of symptoms and daily medication increased during the season with a constant pollen } \\
\text { load. }\end{array}$ \\
\hline
\end{tabular}

FEV1, forced expiratory volume in the first second; FVC, forced vital capacity; PEF, peak expiratory flow.

\section{Risk of bias across the studies}

In the majority of studies, exposure assessment was based on single stationary regional sampler located on the roof level (table 1). Although it has been suggested that different types of pollen sampling can be used to get a rough estimate of pollen exposure, ${ }^{47}$ many of the approaches may not have captured the daily individual exposures at the breathing level in satisfactory detail. In 2013, we monitored grass pollen concentrations at 16 sites in the cities of Helsinki and Espoo during the peak pollen season by using rotorod-type samplers at the breathing height. ${ }^{48}$ We identified substantial variation in exposure concentrations at breathing height according to urbanity of the site and time of the day within areas covered by our roof level monitoring stations. Most valid estimates of pollen exposure could be obtained by using personal pollen sampling. There were also other potential sources of heterogeneity in the exposure measured by these studies linked to variation in weather/climatic conditions, type and period of monitoring, nature of pollen season, daily activities/time spent outdoors by the study subjects, variation in the height of monitoring and pollen types monitored. This heterogeneity in exposure can generate a substantial variation in occurrence and severity of symptoms among exposed subjects. Therefore, we converted individual EEs into a common (comparable) 
pollen concentration, that is, as 10 pollen grains increase per cubic metre of air.

In all studies, selection of study subjects was based on predefined and justified eligibility criteria. Due to the study design that included inference based on withinindividual variation of health outcome, the risk of selection bias is rather small (online supplementary table 2). Also the relatively high follow-up rates (varying from $46.0 \%$ to $100 \%$ ) across studies reduce the risk of selection bias. However, there was substantial diversity in the type and measurement of outcomes, which resulted in difficulties in forming the major outcome groups for the meta-analyses. Status of allergic and/or asthmatic diseases varied from mild to moderate or from moderate to severe.

The studies could be divided roughly into two major groups on the basis of what kind of adjustment was applied for confounding. The first group of studies provided only descriptive results without any or only with very basic statistical analyses. The second group performed extensive statistical analyses, including controlling for a few or several confounders. Due to the study design, where individuals act as their own controls on days with no (major) exposure, individual characteristics were not potential confounders. In contrast, environmental factors, such as temperature and air pollution, can be potential confounders. A significant number of the studies adjusted for temperature (13) and other meteorological parameters (12), as well as for air pollution (4). Other potential sources of heterogeneity include variation in the studied time lags between the exposure and the outcome (varying from 0 to 14 days), potential differences in allergen content of pollen of interest and different characteristics and size of the study populations (varying from 12 to 430 subjects). In 24 studies, the study focused on asthmatics and/or subjects with allergies, whereas two studies included both healthy and nonhealthy subjects. ${ }^{25} 26$

Relations between pollen exposure and allergy-related and asthma-related symptoms among allergic/asthmatic subjects A total of 12 studies were included in the meta-analyses. In eight studies, ${ }^{15} 17202133343839$ the EE was based on OR and in four studies ${ }^{1924-26}$ on a regression coefficient which was or was converted to a change per 10 grains per $\mathrm{m}^{3}$ of air. The summary EE for the relation between pollen exposure and any symptoms was statistically significantly increased at 1.02 (95\% CI 1.01 to 1.03$)$ from the random-effects model (figures 2 and 3 and online supplementary figure 1). The study-specific estimates showed high heterogeneity. This estimate was based on six studies (providing nine EEs). The funnel plot and the results from the Begg's ( $\mathrm{z}=-1.25 ; \mathrm{p}=0.211)$ and Egger's tests (bias coefficient $0.0457453 ; 95 \%$ CI -0.0048418 to 0.0963324 ; $\mathrm{p}=0.070$ ) on short-term pollen exposure and any symptoms provided no indication of publication bias (online supplementary figure 2).

A total of six studies (nine EEs) provided study-specific EEs for pollen exposure and lower respiratory symptoms. The summary EE from the random-effects model was 1.01 (95\% CI 1.00 to 1.02 ). The study-specific estimates showed high heterogeneity.

The summary EE for pollen exposure and upper respiratory symptoms, based on three studies (four EEs), was significantly increased at 1.07 (95\% CI 1.04 to 1.09) from the random-effects model. There was moderate heterogeneity between the study-specific estimates.

The relation between pollen exposure and ocular symptoms was reported in three studies (four EEs). The summary EE from the random-effects model was

\section{Any symptom}

\begin{tabular}{|c|c|c|c|}
\hline Study & & $\mathrm{EE}(95 \% \mathrm{CI})$ & ight $\%$ \\
\hline Ostro (2001) & : & $1.010(0.922,1.106)$ & 1.46 \\
\hline Delfino (2002) - on medication & ; & $0.998(0.977,1.019)$ & 12.28 \\
\hline Delfino (2002) - not on medication & + & $1.009(1.000,1.018)$ & 18.71 \\
\hline Caillaud (2012) & $i$ & $1.054(1.026,1.083)$ & 9.64 \\
\hline DellaValle (2012) - on medication & - & $1.001(0.998,1.004)$ & 20.86 \\
\hline DellaValle (2012) - not on medication & ? & $1.001(0.996,1.006)$ & 20.33 \\
\hline Caillaud (2014b) - in 2009 & & $-1.225(1.109,1.354)$ & 1.22 \\
\hline Caillaud (2014b) - in 2010 & $\rightarrow$ & $1.048(1.025,1.071)$ & 11.84 \\
\hline Caillaud (2014a) & $\longrightarrow$ & $1.109(1.051,1.171)$ & 3.66 \\
\hline Overall $\left(I^{2}=86.9 \%, P=0.000\right)$ & (1) & $1.019(1.007,1.031) 1$ & 100.00 \\
\hline
\end{tabular}

Figure 2 Forest plot for the relation between pollen exposure and any symptom (weights are from random-effects analysis). $E E$, effect estimate. 
A Lower respiratory symptoms

Study

EE $(95 \% \mathrm{CI}) \quad$ Weight $\%$

Ostro (2001)

Delfino - on medication (2002)

Delfino - not on medication (2002)

Caillaud (2012)

DellaValle - on medication (2012)

DellaValle - not on medication (2012)

Caillaud (2014b) - in 2009

Caillaud (2014b) - in 2010

Caillaud (2014a)

\begin{tabular}{l|lllll} 
Overall $\left(I^{2}=\mathbf{6 8 . 3} \%, P=\mathbf{0 . 0 0 1}\right)$ & & \multicolumn{3}{c}{$\mathbf{1 . 0 0 8}(\mathbf{1 . 0 0 0 , 1 . 0 1 5}) \mathbf{1 0 0 . 0 0}$} \\
\hline 0.9 & 1 & 1.1 & 1.2 & 1.3
\end{tabular}

$1.010(0.922,1.106) \quad 0.71$

$0.998(0.977,1.019) \quad 9.41$

$1.009(1.000,1.018) \quad 21.52$

$1.030(1.010,1.050) \quad 10.47$

$1.001(0.998,1.004) \quad 28.79$

$1.001(0.996,1.006) \quad 26.76$

$1.140(1.030,1.250) \quad 0.63$

$1.030(0.910,1.080) \quad 0.80$

$1.120(1.030,1.210) \quad 0.91$

B Upper respiratory symptoms

Study

EE $(95 \% \mathrm{CI}) \quad$ Weight $\%$

Caillaud (2012)

Caillaud (2014b) - in 2010

Caillaud (2014b) - in 2009

Caillaud (2014a)

Overall $\left(I^{2}=28.7 \%, P=0.240\right)$

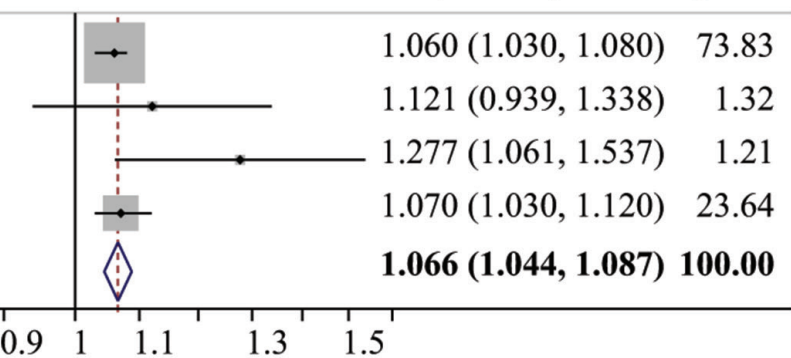

\section{Ocular symptoms}

Study

EE $(95 \% \mathrm{CI}) \quad$ Weight $\%$

Caillaud (2012)

Caillaud (2014b) - in 2009

Caillaud (2014b) - in 2010

Caillaud (2014a)

Overall $\left(I^{2}=80.1 \%, P=0.002\right)$

$1.080(1.050,1.120) 33.63$

$1.320(1.160,1.560) \quad 10.09$

$1.050(1.020,1.070) 35.49$

$1.170(1.080,1.270) 20.80$

$1.109(1.050,1.172) 100.00$

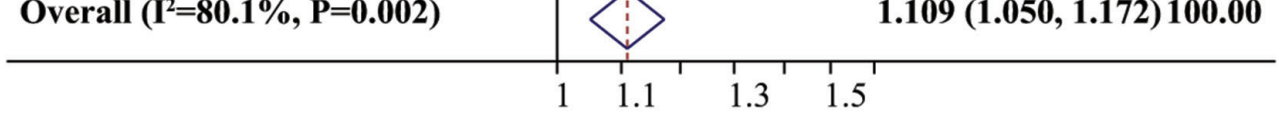

\section{Symptom score}

\begin{tabular}{lrlr} 
Study & EE $(95 \% \mathrm{CI})$ & Weight \% \\
\hline Ross (2002) & $1.001(1.001,1.002)$ & 42.24 \\
Roberts (2005) & $-1.014(1.010,1.018)$ & 13.70 \\
Feo Brito (2007) & $1.026(1.002,1.050)$ & 0.58 \\
Feo Brito (2011) & $1.000(1.000,1.000)$ & 43.48 \\
Overall (I'=94.6\%, P=0.000) & 1 & $\mathbf{1 . 0 0 3}(\mathbf{1 . 0 0 1}, \mathbf{1 . 0 0 4})$ & $\mathbf{1 0 0 . 0 0}$ \\
\hline & 1 & 1.1 &
\end{tabular}

Figure 3 (A) Forest plot for the relation between pollen exposure and lower respiratory symptoms (weights are from randomeffects analysis). (B) Forest plot for the relation between pollen exposure and upper respiratory symptoms (weights are from random-effects analysis). (C) Forest plot for the relation between pollen exposure and ocular symptoms (weights are from random-effects analysis). (D) Forest plot for the relation between pollen exposure and symptom score (weights are from random-effects analysis). EE, effect estimate. 
1.11 (95\% CI 1.05 to 1.17$)$. The study-specific estimates showed high heterogeneity.

The relation between pollen exposure and symptom scores was based on four studies applying linear regression modelling (giving regression coefficients). The summary EE was significantly elevated $(1.003 ; 95 \% \mathrm{CI}$ 1.001 to 1.004$)$. The study-specific estimates showed high heterogeneity.

\section{Relations between pollen exposure and lung function among general population}

The relation between pollen exposure and PEF was assessed in two studies (giving four EEs), resulting in a summary EE of 0.98 for 10 pollen grains increase per cubic metre of air (95\% CI 0.95 to 1.01 ) in the randomeffects model based on linear regression modelling. The study-specific estimates showed large heterogeneity.

Two studies estimated the relation between pollen exposure and FEV. One study used FEV in the first second, FEV1 as the outcome and the other FEV at 3/4 of a second, FEV 0.75. Different FEV estimates were combined in the analysis. Meta-analysis gave the summary $\mathrm{EE}$ of 1.00 for 10 pollen grains increase per cubic metre of air (95\% CI 0.99 to 1.01) in the fixed-effects model based on linear regression modelling. There was little heterogeneity between the studies.

\section{Relations between pollen exposure and use of allergy and/or asthma medication}

In two studies, the use of allergy and/or asthma medication was combined with information on allergy and/or asthma symptoms (in forming symptom-medication score). In five studies that investigated the relation between pollen exposure and the use of medication, pollen exposure increased the use of medication. In contrast, three studies did not show any association between pollen exposure and use of allergy/asthma medication.

\section{DISCUSSION \\ Main findings}

This systematic review and meta-analysis provides new evidence that short-term pollen exposure significantly increases the risk of allergic and asthmatic symptoms. The summary EE for a 10 grains $/ \mathrm{m}^{3}$ increase in pollen exposure showed on average a $2 \%$ increase in the risk of any allergic or asthmatic symptom. The corresponding increases in the risk of upper respiratory symptoms and ocular symptoms were $7 \%$ and $11 \%$, respectively. All summary EEs were statistically significant. This meta-analysis did not show any statistically significant relations between pollen exposure and lung function measurements. The summary EE for 10 grains $/ \mathrm{m}^{3}$ increase in pollen exposure indicated a $2 \%$ decrease in PEF values, while no change was detected in relation to FEV values.

\section{Validity of results}

The strengths of our study include identification of individual studies based on a clearly defined search strategy. In addition to the primary PubMed and Scopus database searches, we also used secondary references that were cited by the articles and reviews identified in the primary search to achieve as complete set of studies as possible. Two reviewers checked independently the eligibility of the studies according to a priori set inclusion and exclusion criteria and identified the most appropriate EE.

The present systematic review and meta-analysis focused on panel studies mainly with relatively brief follow-up periods. The follow-up periods in the studies varied from 3 to 52 weeks. However, pollen-related allergic and asthmatic symptoms are usually induced after only a few hours or days of exposure. ${ }^{49}{ }^{50}$ Thus, variable and/or relatively short follow-up periods are probably not problematic when assessing the relationship between pollen exposure and outcomes of interest in this study.

Our statistical analyses included 12 studies, because only 12 studies out of a total of 26 presented the exact mean or IQR values of pollen grains per cubic metre. Information on the mean and IQR values were needed to convert the study-specific EEs into common EEs for exposure corresponding to 10 pollen grains increase per cubic metre. The aim of this transformation was to make studies containing different pollen concentration values comparable. Although the total number of panel studies was reasonable, the numbers of studies available for the subanalyses investigating various outcomes were quite low. Therefore, the conclusions based on results of the subanalyses should be interpreted with caution. NOS scoring gave varying values, indicating partly the low quality of included studies. Although it can reduce the confidence of the results, we did not see any major difference between the EEs of the lower and higher scored studies.

'Any exposure' was applied in the analyses due to the heterogeneity of exposure assessment. Total daily mean pollen concentration values were preferred, but when such were not available, information on the mean daily airborne concentration of distinct pollen types (birch, grass, ragweed, mugwort, olive, elm and/or hazel/alder) was used as the measure of exposure in the analyses. This should not cause any problem, because the pollen seasons of different pollen types commonly overlap, so individuals can react to exposure to several pollen types. Consequently, the reaction to pollen exposure is likely to be a combined reaction to a sum of various pollen types. ${ }^{51}$ It is not always possible to define exactly which specific pollen type caused the symptoms. Therefore, the exact separation of distinct pollen types in health effect studies is somewhat artificial and thus, unnecessary.

\section{Synthesis with previous knowledge}

Our results indicated that short-term pollen exposure increases the risk of any respiratory or other allergic symptom, lower and upper respiratory symptoms and 
ocular symptoms among allergic and/or asthmatic subjects. Depending on the plant species, concentrations of pollen grains in the breathing air can vary between zero and thousands. Eventually, increases in pollen exposure can have a considerable effect on the well-being of allergic/asthmatic people. In a recent systematic review and meta-analysis of 14 studies, ${ }^{52}$ the mean number of emergency department attendance among children and adolescents with asthma increased $1.88 \%$ (95\% CI $0.94 \%$ to $2.82 \%$ ) in relation to a 10 grass pollen grain increase per cubic metre. These results are in line with a recent ecological study from Japan, where a positive association was observed between cedar and cypress pollen counts and the prevalence of symptoms of allergic rhinoconjunctivitis and asthma in school children. ${ }^{53}$ Similarly, our results are also in line with the register-based time-series analysis among Belgian population, where a positive association was observed between pollen exposure and allergy medication sales. ${ }^{54} \mathrm{~A}$ time-stratified case-crossover study showed a positive association between tree and weed pollen exposure and emergency department visits due to asthma exacerbations among US asthmatics aged $13-17$ years old. ${ }^{55}$

According to our results, the effect of pollen exposure was stronger in upper respiratory tract than in lower respiratory tract. This could be explained by the large size of the pollen grain. Generally, the size of pollen varies between 20 and 100 micrometres in diameter. ${ }^{56}$ Therefore, particles of pollen grain size do not penetrate well into the lower respiratory tract. ${ }^{57}$ Pollen grains are likely to adhere and release their allergenic content already in the upper respiratory tract. As a consequence of this, the majority of the direct allergic inflammatory effects caused by pollen may be experienced in the region of the upper respiratory tract.

Our systematic review did not detect any major effect of pollen exposure on lung function. The results may be explained by the fact that the study population for lung function effects included healthy people in addition to allergic and asthmatic subjects. If these studies would only include allergic and/or asthmatic persons, more pronounced effects might be detected. In the Swedish cohort-based study, exposure to grass pollen during the preceding day was associated with a reduced FEV in relation to an increase in three pollen counts (/ $\mathrm{m}^{3}$ ) among 8-year-old children. ${ }^{58}$ This association was more pronounced among children who were sensitised to pollen allergens. In line with those results, another study of Swedish adults showed that pollen exposure resulted in significantly increased concentration of NO in exhaled air, which suggested increased airway inflammation among these asthmatics compared with the healthy controls. ${ }^{59}$

\section{CONCLUSIONS}

This systematic review and meta-analysis provides new evidence that short-term exposure to pollen grains increases any respiratory symptoms, as well as specifically upper respiratory and ocular symptoms among allergic and asthmatic subjects. It is important that clinicians take into account, when working with allergic and asthmatic patients that even relatively short-term exposure to pollen can induce for them symptoms of allergies and asthma. Clinicians should advise allergic and asthmatic subjects to avoid spending much time outdoors during the (main) pollen periods, and to use adequate allergy and asthma medications when such exposures cannot be avoided. Future studies should use personal exposure assessment and it would be important to find out how the variation in pollen exposure affects the health of allergic and asthmatic subjects.

Acknowledgements We thank Riitta Aittamaa for her valuable assistance with figure editing. We also thank the organising committee of the 6th European Symposium on Aerobiology held in Lyon, France, July 2016 to possibility to present the main results of the study.

Contributors JJKJ and TTH conceived the study. MAK, DRY and TTH reviewed the articles, NS and MAK analysed the data under supervision of JJKJ. MAK, TTH, MSJ and JJKJ wrote the manuscript. All authors contributed to the intellectual content and approved the final version.

Funding This work was supported by the Research Council for Health, the Academy of Finland (grant numbers 266314, 267675, 267995 (APTA Consortium) and 24302585 (GLORIA Consortium)), and the University of Oulu Strategic Funding.

Disclaimer The funders had no role in study design, data collection or analysis, decision to publish, or preparation of the manuscript.

Competing interests None declared.

Patient consent for publication Not required.

Provenance and peer review Not commissioned; externally peer reviewed.

Data availability statement Data are available on reasonable request.

Open access This is an open access article distributed in accordance with the Creative Commons Attribution Non Commercial (CC BY-NC 4.0) license, which permits others to distribute, remix, adapt, build upon this work non-commercially, and license their derivative works on different terms, provided the original work is properly cited, appropriate credit is given, any changes made indicated, and the use is non-commercial. See: http://creativecommons.org/licenses/by-nc/4.0/.

\section{ORCID iD}

Jouni J K Jaakkola http://orcid.org/0000-0003-4168-4683

\section{REFERENCES}

1 Masoli M, Fabian D, Holt S, et al. The global burden of asthma: Executive summary of the GINA dissemination Committee report. Allergy 2004;59:469-78.

2 Bousquet J, Khaltaev N, Cruz AA, et al. Allergic Rhinitis and its Impact on Asthma (ARIA) 2008 update (in collaboration with the World Health Organization, GA(2)LEN and AllerGen). Allergy 2008;86:8-160.

3 Ozdoganoglu T, Songu M. The burden of allergic rhinitis and asthma. Ther Adv Respir Dis 2012;6:11-23.

4 Ait-Khaled N, Pearce N, Anderson HR, et al. Global map of the prevalence of symptoms of rhinoconjunctivitis in children: the International study of asthma and allergies in childhood (Isaac) phase three. Allergy 2009;64:123-48.

5 Reddel HK, Bateman ED, Becker A, et al. A summary of the new GINA strategy: a roadmap to asthma control. Eur Respir J 2015;46:622-39.

6 Bauchau V, Durham SR. Prevalence and rate of diagnosis of allergic rhinitis in Europe. Eur Respir J 2004;24:758-64.

7 To T, Stanojevic S, Moores G, et al. Global asthma prevalence in adults: findings from the cross-sectional World health survey. BMC Public Health 2012;12:204.

8 Nathan RA, Meltzer EO, Derebery J, et al. The prevalence of nasal symptoms attributed to allergies in the United States: findings from 
the burden of rhinitis in an America survey. Allergy Asthma Proc 2008:29:600-8.

9 National Health Interview Survey (NHIS) Data. Most recent asthma data. The centers for disease control and prevention, 2016. https:// www.cdc.gov/asthma/most_recent_data.htm

10 Wang X-Y, Ma T-T, Wang X-Y, et al. Prevalence of pollen-induced allergic rhinitis with high pollen exposure in grasslands of northern China. Allergy 2018;73:1232-43.

11 Blomme K, Tomassen $\mathrm{P}$, Lapeere $\mathrm{H}$, et al. Prevalence of allergic sensitization versus allergic rhinitis symptoms in an unselected population. Int Arch Allergy Immunol 2013;160:200-7.

12 Darrow LA, Hess J, Rogers CA, et al. Ambient pollen concentrations and emergency department visits for asthma and wheeze. J Allergy Clin Immunol 2012;130:630-8.

13 Annesi-Maesano I, Rouve S, Desqueyroux H, et al. Grass pollen counts, air pollution levels and allergic rhinitis severity. Int Arch Allergy Immunol 2012;158:397-404.

14 Feo Brito F, Mur Gimeno P, Carnés J, et al. Grass pollen, aeroallergens, and clinical symptoms in Ciudad real, Spain. J Investig Allergol Clin Immunol 2010;20:295-302.

15 DellaValle CT, Triche EW, Leaderer BP, et al. Effects of ambient pollen concentrations on frequency and severity of asthma symptoms among asthmatic children. Epidemiology 2012;23:55-63.

16 Taylor PE, Jacobson KW, House JM, et al. Links between pollen, atopy and the asthma epidemic. Int Arch Allergy Immunol 2007;144:162-70.

17 Caillaud D, Thibaudon M, Martin S, et al. Short-Term effects of airborne ragweed pollen on clinical symptoms of hay fever in a panel of 30 patients. $J$ Investig Allergol Clin Immunol 2014a;24:249-56.

18 Häfner D, Reich K, Matricardi PM, et al. Prospective validation of 'Allergy-Control-SCORE(TM)': a novel symptom-medication score for clinical trials. Allergy 2011:66:629-36.

19 Roberts G, Mylonopoulou M, Hurley C, et al. Impairment in quality of life is directly related to the level of allergen exposure and allergic airway inflammation. Clin Exp Allergy 2005;35:1295-300.

20 Delfino RJ, Zeiger RS, Seltzer JM, et al. Association of asthma symptoms with peak particulate air pollution and effect modification by anti-inflammatory medication use. Environ Health Perspect 2002;110:A607-17.

21 Ostro B, Lipsett M, Mann J, et al. Air pollution and exacerbation of asthma in African-American children in Los Angeles. Epidemiology 2001;12:200-8

22 Baraldi E, CARRÀ S, Dario $\mathrm{C}$, et al. Effect of natural grass pollen exposure on exhaled nitric oxide in asthmatic children. Am J Respir Crit Care Med 1999;159:262-6.

23 Delfino RJ, Zeiger RS, Seltzer JM, et al. The effect of outdoor fungal spore concentrations on daily asthma severity. Environ Health Perspect 1997:105:622-35.

24 Ross MA, Persky VW, Scheff PA, et al. Effect of ozone and Aeroallergens on the respiratory health of asthmatics. Arch Environ Health 2002;57:568-78.

25 Scarlett JF, Abbott KJ, Peacock JL, et al. Acute effects of summer air pollution on respiratory function in primary school children in southern England. Thorax 1996;51:1109-14.

26 Studnicka MJ, Frischer T, Meinert R, et al. Acidic particles and lung function in children. A summer cAMP study in the Austrian Alps. Am J Respir Crit Care Med 1995;151:423-30.

27 Roberts G, Hurley C, Bush A, et al. Longitudinal study of grass pollen exposure, symptoms, and exhaled nitric oxide in childhood seasonal allergic asthma. Thorax 2004;59:752-6.

28 Caillaud D, Toloba $Y$, Raobison R, et al. [Health impact of exposure to pollens: A review of epidemiological studies]. Rev Mal Respir 2014b;31:142-9.

29 Newhouse CP, Levetin E. Correlation of environmental factors with asthma and rhinitis symptoms in Tulsa, OK. Annals of Allergy, Asthma \& Immunology 2004;92:356-66.

30 Moher D, Liberati A, Tetzlaff J, et al. Preferred reporting items for systematic reviews and meta-analyses: the PRISMA statement. PLOS Med 2009;6:e1000097.

31 Begg CB, Mazumdar M. Operating characteristics of a RANK correlation test for publication bias. Biometrics 1994;50:1088-101.

32 Egger M, Smith GD, Schneider M, et al. Bias in meta-analysis detected by a simple, graphical test. BMJ 1997;315:629-34.

33 Caillaud DM, Martin S, Segala C, et al. Nonlinear short-term effects of airborne Poaceae levels on hay fever symptoms. J Allergy Clin Immunol 2012;130:812-4.
34 Caillaud D, Martin S, Segala C, et al. Effects of airborne birch pollen levels on clinical symptoms of seasonal allergic rhinoconjunctivitis. Int Arch Allergy Immunol 2014c;163:43-50.

35 Delfino RJ, Coate BD, Zeiger RS, et al. Daily asthma severity in relation to personal ozone exposure and outdoor fungal spores. Am J Respir Crit Care Med 1996;154:633-41.

36 Djukanović R, Feather I, Gratziou C, et al. Effect of natural allergen exposure during the grass pollen season on airways inflammatory cells and asthma symptoms. Thorax 1996;51:575-81.

37 Domínguez-Vilches E, Cariñanos P, Soldevilla CG, et al. Airborne pollen concentrations, solid particle content in the air and allergy symptoms in Córdoba (Spain). Aerobiologia 1995;11:129-35.

38 Feo Brito F, Mur Gimeno P, Martínez C, et al. Air pollution and seasonal asthma during the pollen season. A cohort study in Puertollano and Ciudad real (Spain). Allergy 2007:62:1152-7.

39 Feo Brito F, Gimeno PM, Carnés J, et al. Olea europaea pollen counts and aeroallergen levels predict clinical symptoms in patients allergic to olive pollen. Ann of Allerg Asthma Im 2011;106:146-52.

40 Grammer L, Wiggins C, Shaughnessy MA, et al. Absence of nasal priming as measured by rhinitis symptom scores of ragweed allergic patients during seasonal exposure to ragweed pollen. allergy asthma proc 1990;11:243-6.

41 Jantunen J, Saarinen K, Rantio-Lehtimäki A. Allergy symptoms in relation to alder and birch pollen concentrations in Finland. Aerobiologia 2012;28:169-76.

42 Klabuschnigg A, Götz M, Horak F, et al. Influence of aerobiology and weather on symptoms in children with asthma. Respiration 1981;42:52-60.

43 Krämer U, Weidinger S, Darsow U, et al. Seasonality in symptom severity influenced by temperature or grass pollen: results of a pane study in children with eczema. J Invest Dermatol 2005;124:514-23.

44 Petersen BN, Sandberg I. Diagnostics in allergic diseases by correlating pollen/fungal spore counts with patient scores of symptoms. Grana 1981:20:219-23.

45 Schäppi GF, Taylor PE, Kenrick J, et al. Predicting the grass pollen count from meteorological data with regard to estimating the severity of hayfever symptoms in Melbourne (Australia). Aerobiologia 1998;14:29-37.

46 Taudorf E, Moseholm L. Pollen count, symptom and medicine score in birch pollinosis. A mathematical approach. Int Arch Allergy Appl Immunol 1988;86:225-33.

47 Riediker M, Keller S, Wüthrich B, et al. Personal pollen exposure compared to stationary measurements. J Investig Allergol Clin Immunol 2000;10:200-3.

48 Hugg $\mathrm{TT}$, Hjort J, Antikainen $\mathrm{H}$, et al. Urbanity as a determinant of exposure to grass pollen in Helsinki metropolitan area, Finland. PLoS One 2017; 12:e0186348.

49 Osborne NJ, Alcock I, Wheeler BW, et al. Pollen exposure and hospitalization due to asthma exacerbations: daily time series in a European City. Int J Biometeorol 2017;61:1837-48.

50 Robertson DG, Kerigan AT, Hargreave FE, et al. Late asthmatic responses induced by ragweed pollen allergen. J Allergy Clin Immunol 1974:54:244-54.

51 D'Amato G, Cecchi L, Bonini S, et al. Allergenic pollen and pollen allergy in Europe. Allergy 2007;62:976-90.

52 Erbas B, Jazayeri M, Lambert KA, et al. Outdoor pollen is a trigger of child and adolescent asthma emergency department presentations: a systematic review and meta-analysis. Allergy 2018;73:1632-41.

53 Yoshida K, Adachi Y, Akashi M, et al. Cedar and cypress pollen counts are associated with the prevalence of allergic diseases in Japanese schoolchildren. Allergy 2013;68:757-63.

54 Guilbert A, Simons K, Hoebeke L, et al. Short-Term effect of pollen and spore exposure on allergy morbidity in the Brussels-Capital region. Ecohealth 2016;13:303-15.

55 Gleason JA, Bielory L, Fagliano JA. Associations between ozone, PM2.5, and four pollen types on emergency department pediatric asthma events during the warm season in New Jersey: a casecrossover study. Environ Res 2014;132:421-9.

56 Haahtela T, Sorsa P. Kasviallergiat ja allergiakasvit [Plant allergies and allergenic plants; in Finnish. Helsinki: Kirjayhtymä, 1999.

57 Suphioglu C, Singh MB, Taylor P, et al. Mechanism of grass-polleninduced asthma. The Lancet 1992;339:569-72.

58 Gruzieva O, Pershagen G, Wickman M, et al. Exposure to grass pollen - but not birch pollen - affects lung function in Swedish children. Allergy 2015;70:1181-3.

59 Bake B, Viklund E, Olin A-C. Effects of pollen season on central and peripheral nitric oxide production in subjects with pollen asthma. Respir Med 2014;108:1277-83. 